British Heart Fournal, 1978, 40, 817-819

\title{
Aortic valve replacement during acute rheumatic fever
}

\author{
A. KHAN, S. CHI, AND L. GONZALEZ-LAVIN \\ From the Divisions of Cardiothoracic Surgery and Pediatric Cardiology, \\ College of Human Medicine, Michigan State University, East Lansing, Michigan, and \\ Ingham Medical Center, Lansing, Michigan
}

SUMMARY Emergency aortic valve replacement was performed during an attack of acute rheumatic fever in a 12-year-old black boy. He had an uneventful recovery and has remained asymptomatic 27 months after operation. In the light of this experience and that of others, one might conclude that the decision to operate on these patients should be based on the severity of the haemodynamic derangement rather than on the state of activity in the rheumatic process.

Notwithstanding the general belief that active rheumatic heart disease is a relative contraindication to cardiac surgery, recent reports have shown the value of valvular replacement in selected patients with acute rheumatic fever (Timmis et al., 1966; Gersony et al., 1968; Kloth et al., 1969; Strauss et al., 1974). Certain children with rheumatic fever have an extremely poor prognosis with medical therapy (Taranta et al., 1962; Harris et al., 1966), and guidelines can be established to single out patients who will need and greatly benefit from early surgical intervention (Strauss and Goldring, 1974; Strauss et al., 1974). In this communication we report a patient who had successful aortic valve replacement during an episode of recurrent acute rheumatic fever which produced severe aortic regurgitation and acute left ventricular failure.

\section{Case report}

A 12-year-old black boy was admitted on 1 March 1974. He had a past history of acute rheumatic carditis and arthritis at the age of 8 years. Because of allergy to penicillin, he was discharged on erythromycin and aspirin. He was lost to follow-up until three weeks before the present admission when he developed fever and fatigue, with rising erythrocyte sedimentation rate (ESR) and antistreptolysin O (ASO) titre. Throat cultures were positive for beta-haemolytic streptococcus. Three days before admission to hospital, he developed arthralgia and chest pain.

At admission, examination revealed an ill-looking boy with a temperature of $38.9^{\circ} \mathrm{C}$; blood pressure,
$114 / 50 \mathrm{mmHg}$; pulse, 116 per minute; respiratory rate, 28 per minute. Tenderness, without swelling or inflammatory signs, was noticed over the right elbow and both knees. Examination of the cardiovascular system revealed a grade $4 / 6$ full diastolic murmur in the aortic area, and a grade $2 / 6$ pansystolic murmur at the apex with radiation to the left axilla. Spleen and liver were not enlarged and peripheral oedema was absent.

Laboratory investigations revealed an ESR of $64 \mathrm{~mm} /$ hour and ASO titre of 833 Todd units. C-reactive protein was positive. A test for sicklecell trait was negative. Chest $x$-ray film showed moderate cardiomegaly with some evidence of pulmonary congestion (Fig. 1). The electrocardiogram was unremarkable except for sinus tachycardia. Phonocardiogram showed the previously mentioned murmurs. Echocardiography showed a slight increase in ventricular cavity and left ventricular wall thickness. The left atrium was also slightly enlarged. He was placed on bed rest; digoxin, 0.125 $\mathrm{mg}$ daily after full digitalisation was obtained; and frusemide, 10 to $20 \mathrm{mg}$ a day as treatment for heart failure. The patient was also placed on aspirin, $600 \mathrm{mg}$ every 6 hours and erythromycin, $100 \mathrm{mg}$ twice daily for the acute rheumatic carditis and the streptococcal infection. On the third day after admission prednisone, $20 \mathrm{mg}$ twice a day was added to the previous regimen. The patient remained comfortable for a week. He then developed increasing shortness of breath and became listless. Twelve days after admission he developed acute left ventricular failure with evidence of pulmonary oedema by $x$-ray film (Fig. 2), respirations were 


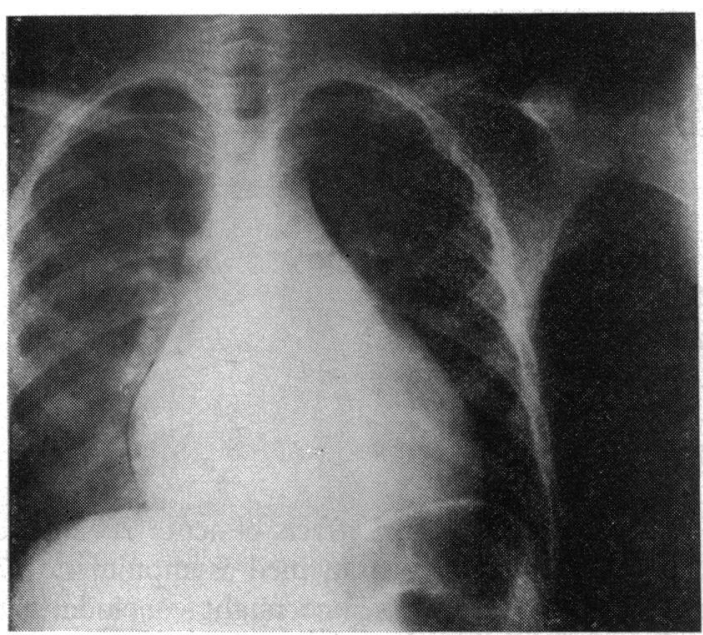

Fig. 1 Chest $\mathrm{x}$-ray film taken on admission showed moderate cardiomegaly with some evidence of pulmonary congestion.

40 to 50 per minute, he was cold and clammy, blood pressure was $80 / 0 \mathrm{mmHg}$ and heart rate was 150 per minute. He showed signs of severe cardiovascular collapse and was taken to the operating room as an emergency.

At operation the pericardial cavity was found to be obliterated by fibrinous adhesions. The myocardium was oedematous with evidence of acute inflammatory changes. Under conventional cardiopulmonary bypass, systemic hypothermia to $28^{\circ} \mathrm{C}$ and local cooling without coronary perfusion, the aortic valve was visualised through an oblique aortotomy. The massive aortic regurgitation had been caused by acute inflammatory changes of the three leaflets which were oedematous with rolled edges failing to coapt during diastole. The valve was replaced with a No. 19 Bjork-Shiley prosthesis.

The postoperative course was smooth with disappearance of pulmonary oedema and hepatomegaly within 48 hours. During the convalescence period be was given aspirin, $600 \mathrm{mg}$ every 6 hours; erythromycin, $100 \mathrm{mg}$ twice a day; and prednisone (which was tapered off 10 days after operation) for the acute rheumatic carditis; oral anticoagulants were used (Coumadin) during the hospital stay. Laboratory results before discharge disclosed an erythrocyte sedimentation rate of 9. C-reactive protein was negative, ASO titre 625 Todd units. He was discharged on digoxin, erythromycin, and aspirin two weeks after operation. The boy appears healthy and completely asymptomatic 27 months after operation. The electrocardiogram and chest $x$-ray film are satisfactory.

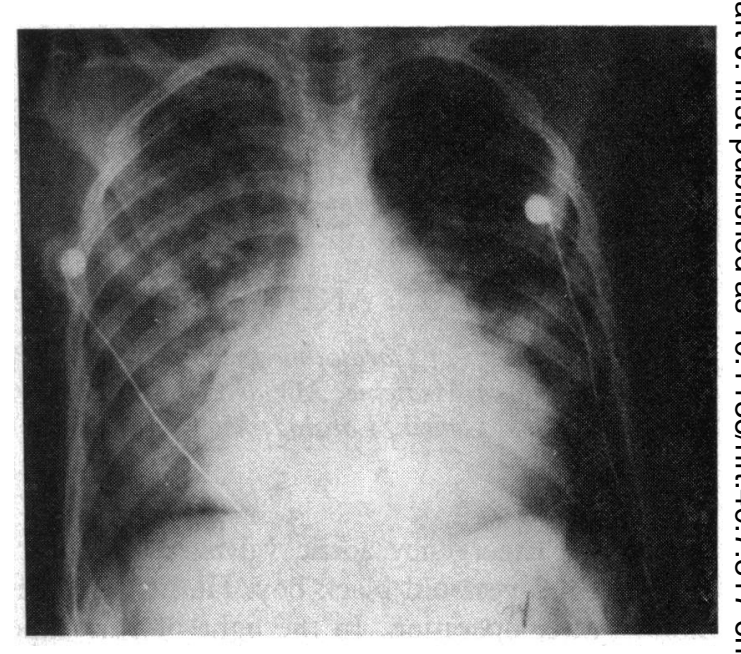

Fig. 2 Chest $\mathrm{x}$-ray film 12 days after hospital admission disclosing cardiomegaly and pulmonary oedema.

On microscopy the specimen showed focal fibrosis and hyalinisation of the stroma of the leaflets with collection of histiocytes and lymphocytes. Aschoff nodules were not present.

\section{Comment}

Severe congestive heart failure in patients with acute rheumatic fever is not only caused by pancarditis but, in some cases, also by severe valvular regurgitation. It is in this particular group of patients that valve replacement is indicated (Timmis et al., $\stackrel{\vec{\sigma}}{-}$ 1966; Gersony et al., 1968; Kloth et al., 1969; Strauss et al., 1974).

Strauss and associates (1974) propose that a child with rheumatic heart disease should be catheterised 0 and considered for operation if he fulfils any one of the following criteria: (a) congestive heart failure and true chronic rheumatic fever; (b) congestive heart failure and cardiothoracic ratio greater than $\Omega$ 0.6 ; (c) functional class IV; or (d) atrial fibrillation. N This and other reports (Van der Horst et al., 1973; ⿱ㅓ Strauss et al., 1974) showed that valve replacement for the correction of haemodynamic derangements 0 produced by severe valvular regurgitation can result $\frac{}{\Phi}$ in an improvement of the patient's condition and in $\stackrel{?}{+}$ some cases, as in our patient, valve replacement is a 7 life-saving measure. In view of the small number of patients who have been operated on during acute $\stackrel{\square}{\Omega}$ rheumatic fever, it is difficult to predict long-term $\stackrel{\vec{\perp}}{\stackrel{\circ}{\circ}}$ results. But, if the results of valve replacement in children during inactive rheumatic heart disease are any guideline, then an expected survival rate of $\frac{0}{0}$ 
72 per cent can be expected 5 years after operation (Strauss et al., 1974). The decision to operate should be based on the severity of disability and haemodynamic disturbance rather than on the active or inactive state of the rheumatic heart disease.

\section{References}

Gersony, W. M., Willerson, W. D., Jr., Johnson, A. F. and Webb, W. R. (1968). Aortic valvuloplasty during acute rheumatic fever. Fournal of Thoracic and Cardiovascular Surgery, 55, 598-602.

Harris, L. C., Nghiem, Q. X., and Schreiber, M. H. (1966). Rheumatic mitral insufficiency in children. American fournal of Cardiology, 17, 194-202.

Kloth, H. H., Reed, G. E., and Spagnuolo, M. (1969). Open heart surgery and active rheumatic carditis: report of a case. Pediatrics, 43, 613-617.

Strauss, A. W., and Goldring, D. (1974). Valve replacement in acute rheumatic heart disease. Fournal of Pediatrics, 84, 786-787.
Strauss, A. W., Goldring, D., Kissane, J., Hernandez, A., Hartmann, A. F., McKnight, C. R., and Weldon, C. S. (1974). Valve replacement in acute rheumatic heart disease. Fournal of Thoracic and Cardiovascular Surgery, 67, 659-670.

Taranta, A., Spagnuolo, M., and Feinstein, A. R. (1962). "Chronic" rheumatic fever. Annals of Internal Medicine, 56, 367-388.

Timmis, H. H., Hardy, J. D., Watson, D. G., and Blake, T. M. (1966). Mitral valve replacement in a child during acute rheumatic carditis. Annals of Surgery, 164, 10341040.

Van der Horst, R. L., leRoux, B. T., Rogers, N. M. A., and Gotsman, M. S. (1973). Mitral valve replacement in childhood. A report of 51 patients. American Heart fournal, 85, 624-634.

Requests for reprints to Professor Lorenzo Gonzalez-Lavin, Division of Cardiothoracic Surgery, Michigan State University, B437 Clinical Center, East Lansing, Michigan 48823, U.S.A. 